\title{
Psychiatric aspects of HIV-1 infection and AIDS
}

\author{
MARIO MAJ*1 \\ From the World Health Organization Division of Mental Health/Global Programme on AIDS, \\ Geneva, Switzerland
}

SYNOPSIS The literature on the psychiatric aspects of HIV-1 infection is reviewed. The whole range of psychiatric disorders described in HIV-1 infected subjects, from HIV-I dementia to adjustment disorders, is covered, along with the AIDS-related psychopathology which may develop in subjects without HIV-1 infection.

\section{INTRODUCTION}

The infection by the human immunodeficiency virus (HIV-1) and the acquired immune deficiency syndrome (AIDS) have become subjects of considerable interest for psychiatrists and mental health workers essentially for two reasons: (1) the tropism of the virus for the central nervous system, which is evident from the fact that more than $70 \%$ of unselected AIDS cases present with neuropathological abnormalities at autopsy (Moskowitz et al. 1984; Nielsen et al. 1984); (2) the dramatic psychological impact of the diagnosis of the infection and of the progression of the disease on affected individuals, which is even enhanced by their usually young age and by their frequent belonging to traditionally stigmatized and marginalized social groups. In view of this double source of interest, it is not surprising that two major research areas can be identified in AIDS psychiatric literature, the former falling on the border between psychiatry and neurology and dealing with the clinical consequences of HIV-I infection of the brain, with special regard to HIV-I dementia, the latter falling on the border between psychiatry and clinical psychology and dealing with acute stress reactions and adjustment disorders in subjects with HIV1 infection.

On the other hand, clinical experience has

\footnotetext{
* Mario Maj is Professor of Mental Hygiene in the Department of Psychiatry at the University of Naples (Italy). This paper was written while he was co-ordinating in Geneva the WHO Programme on Neuropsychiatric Aspects of HIV-I Infection.

1 Address for correspondence: Professor Mario Maj, Division of Mental Health, World Health Organization, 20 Avenue Appia, CH1211 Geneva 27, Switzerland.
}

taught that dementia and acute stress reactions or adjustment disorders are not the only psychiatric conditions that may occur in HIV-1 infected subjects. In particular, two issues have recently attracted the attention of clinicians and research workers: (1) the possibility that HIV-1 dementia be preceded, in the early stages of the infection, by a subtle cognitive dysfunction, only detectable by means of specific neuropsychological tests; (2) the possibility that HIV-1 seropositive subjects develop acute psychotic disorders, even in the absence of any sign of cognitive impairment.

All the above research topics are briefly covered in the present review. Furthermore, considerable attention is paid to the AIDSrelated psychopathology (for instance, hypochondriacal preoccupations or delusions) which may develop in subjects without HIV-I infection.

\section{HIV-1 DEMENTIA}

\section{Aetiology and pathogenesis}

HIV-1 dementia is currently believed to be caused by the infection of the brain with HIV-1 (Navia et al. 1986a). Indeed, Southern blot analysis has shown a high frequency and copy number of proviral DNA in the brains of patients with this condition (Shaw et al. 1985), in situ hybridization has revealed the presence of viral RNA in these brains (Koenig et al. 1986), immunohistochemistry has detected HIV-1 antigens (Gabuzda et al. 1986), electron microscopy has identified viral particles (Epstein et al. 1985), and HIV-1 has been directly cultured from the brain and cerebrospinal fluid (CSF) of demented patients (Ho et al. 1985). The cell types most 
commonly infected are macrophages and macrophage-derived multinucleated cell. Viral antigens have also been detected in cells identified morphologically and histochemically as microglia (Vazeux et al. 1987), whereas it is not clear whether other cell types, including astrocytes, oligodendrocytes, neurons or vascular endothelium, may be infected. The distribution of the infected cells seems to parallel the neuropathological findings (see below), being more prominent in subcortical structures (Pumarola-Sune et al. 1987). It is unclear whether HIV-l enters the brain as a free virus, or within infected monocytes and macrophages, or through primary infection of the choroid plexus or meningeal cells.

The pathogenesis of HIV-1 dementia remains uncertain, although severe immunosuppression seems to be necessary for its development. The paucity or absence of productive infection or lysis of neurons and glial cells suggests processes other than simple destruction of these cells (Price et al. 1988a). The release of toxic substances by infected cells has been postulated: they may be cell-coded products or toxic products of viral genes. Recently, an interference of gp120, the envelope glycoprotein of HIV-1, with the trophic properties of neuroleukin (Lee et al. 1987), and with the function of neurotransmitters such as vasoactive intestinal peptide (VIP) (Sacerdote et al. 1987), has been hypothesized. Moreover, an immune-mediated destruction of myelin, similar to that produced by Visna infection in sheep, has been invoked to explain the rarefaction and vacuolation of the white matter which can occur in HIV-1 dementia (McArthur, 1987). Other recent relevant findings include: (1) the increase of mean CSF levels of quinolinic acid (a neurotoxic intermediate metabolite of tryptophan) in AIDS patients, and the significant correlation between these levels and the stage of HIV-I dementia (Heyes et al. 1989); (2) the decrease of the ratio between brain concentrations of adenosintriphosphate (ATP) and inorganic phosphate (assessed by magnetic resonance spectroscopy) in patients with moderate to severe HIV-1 dementia, suggesting a reduction of brain energy metabolism (Jensen et al. 1989).

Another question relevant to the pathogenesis of HIV-1 dementia is whether there are neurotropic variants of HIV-1. In fact, this virus has a high rate of mutation, and the gene coding for the envelope glycoprotein gp 120 appears to be particularly variable. It has been reported that viral CSF or brain isolates behave differently, in lymphocyte cell cultures, from blood isolates (Gartner et al. 1986).

\section{Symptomatology and course}

The onset of HIV-I dementia is usually insidious. Early symptoms can be subdivided into three groups: cognitive, behavioural and motor (Navia et al. $1986 a$; Price et al. 1988 b). Cognitive symptoms include memory and concentration impairment and mental slowing (missing appointments or needing lists to recall ordinary duties; losing track of conversations or one's own train of thought; having difficulty in following the plot when reading or watching TV; needing additional time and effort to organize thoughts and to complete daily tasks). Behavioural symptoms include apathy, reduced spontaneity, and social withdrawal (indifference to personal and professional responsibilities; reduced work production; reduced frequency of social interactions; complaints of early fatiguability, malaise and loss of sexual drive) Depression, irritability or emotional lability, agitation and psychotic symptoms may more rarely occur. Motor symptoms include loss of balance and co-ordination, clumsiness and leg weakness (being less precise in normal hand activities, such as writing and eating; dropping things more frequently than usual; tripping and falling more frequently than usual; perceiving the need to exercise more care in walking). Routine mental status tests in this early stage may be normal, or show only slowing in verbal or motor responses and/or difficulty in recalling a series of objects after 5 or more minutes. Neurological examination may show tremor (best seen when the patient sustains a posture, such as holding the arms and fingers outstretched), hyper-reflexia (particularly of the lower extremities), ataxia (usually seen only on rapid turns or tandem gait), slowing of rapid alternating movements (of the fingers, wrists or feet), frontal release signs (snout reflex, palmar grasp) or dysarthria. Tests of ocular motility may show interruption of smooth pursuits and slowing or inaccuracy of saccades. According to a recent report (Currie et al. 1989), most patients with HIV-1 dementia show, even in early stages, 
more than $25 \%$ errors when evaluated by a bedside antisaccadic eye movement test.

In the late stages of the disease, there is usually a global deterioration of cognitive functions and a severe psychomotor retardation. Speech is slow and monotonous, with word-finding difficulties and possible progression to mutism. Patients become unable to walk, due to paraparesis, and usually lie in bed indifferent to their illness and their surroundings. Bladder and bowel incontinence are common. Myoclonus and seizures may occur. Pedal paraesthesiae and hypersensitivity may appear, due to concurrent sensory neuropathy. The level of consciousness is usually preserved, except for occasional hypersomnolence.

The course of HIV-I dementia is variable, and no predictor of the pace of progression is currently available. In the study by Navia et al. $(1986 a)$, the mean survival time once severe dementia had been recognized was 1.8 months (range 1-6 months) and the mean total duration of the illness was $4 \cdot 2$ months (range 1-9 months), but these estimates were probably excessively weighted by the severity of the disease in the author's series. In a recent study, Sidtis et al. (1989) provided a preliminary estimate of the rate of progression from the stage 0.5 (equivocal/subclinical) to a stage 1 or greater (definite neurological signs and symptoms) of HIV-1 dementia: by 37 weeks $25 \%$ of the patients had progressed, and by 59 weeks the progression rate was $50 \%$. Janssen (1989) suggested that the progression of HIV-l dementia is slower in patients with AIDS-related complex (ARC) than in those with AIDS. Death in patients with HIV-1 dementia usually occurs as a result of inanition, aspiration pneumonia, or systemic opportunistic infections.

\section{Neuropsychological picture}

Formal neuropsychological examination of patients with HIV-1 dementia usually shows the most prominent impairment in tests of fine motor control (finger tapping and grooved pegboard), rapid sequential problem solving (trail making $\mathrm{A}$ and $\mathrm{B}$, digit symbol), visuospatial problem solving (block design), spontaneity (verbal fluency), and visual memory (visual reproduction). Slowing is the major impairment, but errors and inaccuracies are also present. On the contrary, naming and vocabu- lary skills are largely preserved even in the most advanced cases. This pattern has been regarded as consistent with the clinical and neuropathological picture of a 'subcortical' dementia (Navia et al. 1986a; Tross et al. 1988).

\section{Radiological EEG and laboratory findings}

The predominant neuroradiological finding in HIV-1 dementia is cerebral atrophy: both computed tomography $(\mathrm{CT})$ and magnetic resonance imaging (MRI) demonstrate widened cortical sulci and, less commonly, enlarged ventricles (Navia et al. 1986a). Furthermore, MRI frequently shows diffuse (more rarely, patchy or punctate) high signal intensity in the white matter, which has been found to be partially reversible with improved cognitive function after treatment with azidovudine (AZT) (Olsen et al. 1988). The assessment of the regional cerebral metabolic rate for glucose by positron emission tomography (PET) has been reported to show a relative subcortical (thalamus and basal ganglia) hypermetabolism in early HIV-1 dementia, and cortical and subcortical grey matter hypometabolism in the late stages of the disease (Rottenberg et al. 1987). EEG may be normal or, especially in late stages, show diffuse slowing (Snider et al. 1983).

The most frequent CSF findings in HIV-I dementia are the increase of total proteins (typically in the order of $50-100 \mathrm{mg} / 100 \mathrm{ml}$ ) and of IgG fraction and index (McArthur, 1987). Oligoclonal bands may be present. A mild mononuclear pleocytosis may occur and the ratio between the $\mathrm{T}$-lymphocyte subsets (CD4:CD8) may be reversed. The presence of HIV-1, of HIV-1 specific antibodies and of the HIV-1 antigen p24 can be detected in CSF, although none of these findings is specific enough to be useful for diagnostic purposes (Paul et al. 1989). A CSF/plasma ratio higher than 1 for neopterin and $\beta_{2}$-microglobulin has been also reported (Goebel et al. 1989), and CSF $\beta_{2}$-microglobulin levels have been found to correlate with the stage of dementia (Brew et al. 1989).

\section{Neuropathology}

Gross neuropathological examination of brains from patients with HIV-I dementia reveals cerebral atrophy with sulcal widening and ventricular dilatation, and occasionally men- 
ingeal fibrosis. Microscopic abnormalities are most prominent in central white matter and deep grey structures, with relative sparing of the cortex (Navia et al. 1986b). The most common feature is pallor of the central and periventricular white matter. Rarefaction and, in more severe cases, diffuse or focal microvacuolation of white matter may be detected. Multinucleated cells are seen in the most severe cases: they appear to result from virus-induced cell fusion, and tend to cluster around the microvasculature. Other features include perivascular infiltrates (consisting of macrophages, lymphocytes and microglia along with multinucleated cells) and diffuse astrocytosis.

\section{Epidemiology}

The estimate of the prevalence of HIV-1 dementia is largely influenced by the source from which patients are recruited, the stage of infection and the criteria used for the diagnosis. In a recent paper by Janssen et al. (1989a), all cases of AIDS reported to the Centres for Disease Control (CDC) of Atlanta (USA) from 1 September 1987 to 31 December 1988 were considered. A case of HIV-1 dementia was defined as a person who was HIV-l seropositive and presented with disabling cognitive and/or motor dysfunction in the absence of a condition other than HIV-1 infection that could explain the findings. Of the adults $6.5 \%$ had HIV-1 dementia and $3.0 \%$ were reported to have it as the only early manifestation of AIDS. Previous estimates of the point prevalence of HIV-1 dementia in AIDS patients ranged from 8-16\%, whereas the estimates of the percentage of AIDS patients in whom HIV-1 dementia is the presenting manifestation ranged from $0-3.3 \%$ (WHO, 1988). As expected, the prevalence of HIV-1 dementia is found to be much higher in autopsy series of cases reported to neurologists, reaching the figure of $66 \%$ (Price et al. 1988a).

\section{Differential diagnosis}

In patients with recognized systemic AIDS, the differential diagnosis involves opportunistic infections and neoplasms or metabolic encephalopathies that may cause diffuse cerebral dysfunction. Among opportunistic infections, cryptococcal meningitis, cytomegalovirus encephalitis, herpes simplex encephalitis and cerebral toxoplasmosis are particularly important, whereas, among opportunistic neoplasms, primary CNS lymphoma should be considered. These conditions, as well as the metabolic encephalopathies, can often be distinguished from HIV-1 dementia by their more abrupt onset and rapid evolution, and by the parallel impairment of cognition and consciousness. Moreover, CT and MRI can be useful in demonstrating the cerebral atrophy and white matter abnormalities that are characteristic of HIV-I dementia, and CSF examination can be decisive especially in ruling out cryptococcal meningitis. However, it is important to stress that the above disorders may coexist with HIV1 dementia in AIDS patients (Price et al. 1988 b).

In patients without recognized AIDS, the differential diagnosis is more difficult, involving multiple sclerosis, Parkinson's disease, Alzheimer's disease, and mood or psychotic disorders. Therefore, in the presence of a clinical picture resembling that described above, a search for risk factors for AIDS should be pursued, and, if present, HIV-1 serological testing should be always considered (Price et al. 1988b).

\section{Treatment}

A beneficial effect of the antiviral agent azidovudine (AZT) on several cognitive measures in patients with HIV-1 dementia has been demonstrated in one open (Yarchoan et al. 1987) and one double-blind placebo-controlled trial (Schmitt et al. 1988), but not confirmed in another placebo-controlled investigation (Grant et al. 1987a). One of the main disadvantages of this drug is bone marrow suppression. Further studies are clearly required to establish the impact of such treatment, especially in the longterm. At present, therapy of HIV-1 dementia is essentially limited to the management of symptoms and the provision of psychosocial support to the patients and their carers. The use of tricyclic antidepressants should be avoided, because they may provoke or exaggerate delirium. In individuals with marked apathy and psychomotor retardation, a short trial with psychostimulants may be useful.

The care of patients with HIV-1 dementia will make increasing demands on health services, as well as on volunteer and community support systems. It is uncertain, at present, whether such care is best provided in specialized units (e.g. inpatient AIDS units), or within general psy- 
chiatric or medical services. Special management problems may arise when the behavioural disturbance (e.g. poor impulse control, sexual acting-out behaviour or biting) is such as to constitute a risk for other patients or staff members (Raphael et al. 1989). Placement of patients in the terminal stage of the disease may also represent a problem: the lack of appropriate options in the community may obstruct their timely and humane discharge from hospital (Raske, 1988).

\section{NEUROPSYCHOLOGICAL IMPAIRMENT WITHOUT DEMENTIA}

\section{Pattern and prevalence}

The presence of neuropsychological abnormalities in a substantial proportion of symptomatic HIV-1 seropositive subjects, not showing the clinical picture of HIV-1 dementia, has been repeatedly reported, whereas the occurrence of such abnormalities in HIV-1 seropositive otherwise asymptomatic individuals is currently debated.

Tross et al. (1988) applied a battery of neuropsychological tests in four groups of subjects: 44 newly diagnosed AIDS patients, 40 AIDS patients referred for neurological consultation, 16 asymptomatic HIV-1 seropositives, and $20 \mathrm{HIV}-1$ seronegative controls. The two AIDS groups showed a worse performance than both non-AIDS groups in tests of visuo-spatial ability (block design), sequential problem solving (trail making $\mathrm{A}$ and $\mathrm{B}$, digit symbol) and fine motor control (grooved pegboard), and the late AIDS group was also distinguishable from the other groups on a test of motor speed (finger tapping). No significant difference was observed between asymptomatic HIV-1 seropositives and HIV-1 seronegative controls. When the subjects were subdivided into those with severe impairment (four or more abnormal test scores), mild impairment (two or three abnormal test scores) and low impairment (no or one abnormal test score), no HIV-1 seronegative individual showed either mild or severe impairment, whereas one asymptomatic HIV-1 seropositive showed mild and one severe impairment.

Somewhat different results have been obtained by Grant et al. (1987 b), who studied 15 patients with AIDS, 13 patients with AIDS-related complex (ARC), 16 asymptomatic HIV-1 sero- positives and $11 \mathrm{HIV}-1$ seronegative controls. AIDS patients performed significantly worse than the other three groups on a neuropsychological measure of attention and speed of information processing, and significantly worse than HIV-1 seronegatives on a measure of nonverbal abstracting ability. No significant difference was observed between asymptomatic HIV1 seropositives and HIV-1 seronegatives. Nevertheless, when the performance of each subject was classified as abnormal (i.e. definitely impaired on at least one test or probably impaired on at least two tests), the percentage of abnormality was $87 \%$ in AIDS patients, $54 \%$ in patients with ARC, $44 \%$ in asymptomatic HIV-1 seropositives and $9 \%$ in HIV-1 seronegatives.

More recently, Janssen et al. (1989 b) evaluated 26 patients with ARC, 31 patients with generalized lymphadenopathy, 43 asymptomatic HIV-1 seropositives and 157 HIV-I seronegatives. The ARC group was the only one to show significant differences with respect to the HIV-1 seronegative group (worse performance on tests of memory and perceptual speed). Defining abnormality as a performance worse than the cut-off score ( 1 or 1.5 S.D. of the mean of the control group) on tests of two or more functional domains (among the following: memory, perceptual speed, scanning, motor, language), significantly more ARC patients than HIV-1 seronegatives had an abnormal neuropsychological performance, whereas neither patients with generalized lymphadenopathy nor HIV-1 seropositive asymptomatics differed significantly from HIV-1 seronegatives. Using the cut-off point of 1.5 , the percentage of asymptomatic HIV-1 seropositives with an abnormal performance was $14 \%$, and that of HIV1 seronegatives $12 \%$.

Consistent with these last data are the preliminary results of the large Multicentre AIDS Cohort Study (MACS). Selnes et al. (1989) reported that, by using a comprehensive neuropsychological battery, no significant difference on any measure was observed between 225 asymptomatic HIV-1 seropositives and 181 HIV-1 seronegatives. Less than $10 \%$ of seropositives had abnormal performances (cut-off score 2 S.D. of the mean of the seronegative group) on individual subtests, which did not differ significantly from HIV-1 seronegatives. 
No significant difference in the performance on neuropsychological tests between HIV-1 seropositive asymptomatic subjects and HIV-1 seronegative controls has been also found by Goethe et al. (1989), whereas Perry et al. (1989) reported that the number of HIV-1 seropositive asymptomatic subjects with one or more neuropsychological test scores below the sample mean was significantly higher than that of HIV-1 seronegative controls.

\section{Methodological issues}

Comparability of the results of the studies in this area is hampered by several factors: differences in the domains assessed by the various authors and in the instruments used to assess similar domains; dissimilarity of the populations and of the sample sizes; different approaches used in the analysis of data and in the definition of thresholds for abnormality; different attention to cofactors (such as psychiatric symptomatology, substance abuse, prescribed medication, history of childhood learning difficulties or CNS traumas). Moreover, the group of asymptomatic HIV-1 seropositives is likely to be heterogeneous from the immunological viewpoint, and subjects with immunological decline may have a worse cognitive performance (Goethe et al. 1989), which may explain in part the disagreement existing in the literature. In any case, the relationship between neuropsychological impairment in early stages of HIV-1 infection and the subsequent development of HIV-1 dementia remains to be established by means of longitudinal studies.

\section{DELIRIUM}

Delirium has been described within the context of HIV-I dementia (Price et al. 1988a) and of the aseptic meningitis which may develop upon seroconversion (McArthur, 1987). Moreover, its occurrence in AIDS patients may be related to hypoxia (for instance, from Pneumocystis carinii pneumonia), cryptococcal meningitis, systemic infections (such as staphylococcal bacteraemia), space occupying lesions of the brain (such as CNS lymphoma or brain abscesses due to toxoplasmosis), metabolic derangements (disorders of fluid, electrolyte or acid-base balance), and the use of psychotropic drugs (especially tricyclic antidepressants, whose central anti- cholinergic activity seems to be more pronounced in such patients).

The clinical picture of delirium is characterized by clouding of consciousness with reduced capacity to shift, focus and sustain attention to environmental stimuli; perceptual disturbances (misinterpretations, illusions and hallucinations); disorientation and memory impairment; incoherent speech; insomnia; increased (more rarely decreased) psychomotor activity. The syndrome usually develops over a short period of time (hours to days) and its intensity tends to fluctuate during the course of a day. Complete recovery is the rule in delirium occurring at the time of seroconversion. Delirium superimposed on HIV-I dementia may aggravate its course (Price et al. 1988a).

There is no available estimate of the prevalence and incidence of delirium in HIV-1 infection. Management of the syndrome consists in treating the underlying cause, maintaining fluid and electrolyte balance and nutrition, providing sedation, correcting disturbances of sleep-wake cycle, supplying a quiet environment and nursing support directed towards reorientation.

\section{ACUTE STRESS REACTIONS}

\section{Psychological background}

Acute stress reactions may occur in any phase of HIV-1 infection, especially in coincidence with changes in the individual's clinical state. However, they are most common immediately after the diagnosis of the infection.

Psychological reactions to the diagnosis of HIV-1 infection resemble those commonly described in response to the diagnosis of cancer or other life-threatening diseases. They also reflect, however, the specific psychosocial dimensions relevant to AIDS, such as the stigma associated with homosexuality and drug abuse, and the society's fear of contagion. In practice, subjects receiving the diagnosis are suddenly confronted not only with the likelihood of developing a disease with a very poor prognosis and for which no effective therapy is available, but also with several other issues: revealing their homosexuality or drug abuse to family, friends and colleagues; dealing with the fears of partner, family, friends and public; avoiding transmitting the infection to others and protecting themselves 
from opportunistic infections (Christ et al. 1988; Miller, 1988). The age at which the diagnosis is usually made has been regarded as another traumatic factor: most subjects are 25- to 49years-old, an age group that does not expect to develop a potentially fatal illness (Christ et al. 1988). For all the above reasons, it is not surprising that acute stress reactions have been reported in up to $90 \%$ of subjects with a recent diagnosis of HIV-1 infection (WHO, 1988).

The occurrence of acute stress reactions has been found to be particularly frequent in subjects lacking a partner or living in a rural environment, and, according to a report from Germany (Seidl \& Goebel, 1987), to be more common in homosexuals than in drug abusers. On the other hand, no increased overall levels of distress have been reported in a population where most individuals had correctly predicted their test results (Stempel et al. 1987), and it has been maintained that for some patients who had been chronically ill, but not easily classifiable or manageable, the news of the diagnosis may even be greeted with a sense of relief, because they have at last something concrete to fight, and can be enrolled in promising experimental treatment programmes (Miller \& Green, 1986).

\section{Clinical manifestations}

A state of shock, in which the subject feels confused and bewildered, with the mind in constant turmoil, and in which depersonalization, derealization and sleep disorders may occur, has been found to be frequently the initial reaction to the diagnosis (Deuchar, 1984). Other emotional and behavioural reactions may include anger (at being 'caught out', over inability to change circumstances, over lacking or confusing information from staff), which may be expressed by abusive language or even physical aggression, and be directed towards society, old or contemporary sexual partners, family or health care givers; withdrawal (distancing from the present issues and circumstances, losing interest in human contact, "hiding beneath the bedsheets'); guilt (the search for a reason for being 'singled out' leads to the belief that the illness is a retribution for homosexuality or drug abuse); denial (an attitude of indifference, which may lead to a dangerous disregard for medical advice); fear (of death or disfigurement; of losing cognitive or physical abilities; of isolation, abandonment, social or sexual rejection; of infecting others; of family's or partner's inability to cope); despair (Morin et al. 1984; Dilley et al. 1985; Miller, 1987). These reactions may involve the appearance of somatic symptoms, that can be interpreted by the subject as evidence of a physical decline (Nichols, 1985). Bodily checking for signs of progression of the infection has been also described (Holland \& Tross, 1985). Finally, the diagnosis may be followed by suicidal ideation or attempts, substance abuse, or highrisk activities (Holland \& Tross, 1985; Muluka, 1988; Rundell et al. 1988). In the absence of adequate management, acute stress reactions may last several weeks or longer (WHO, 1988).

\section{Management}

The management of psychological reactions to the diagnosis of HIV-1 infection is based on preand post-test counselling. Pre-test counselling involves: (1) helping the subject to analyse the reasons for wanting the test and to evaluate the likelihood that he/she is infected; (2) explaining that the test is not expected to provide a diagnosis of AIDS or any information concerning severity of the infection, infectiousness or prognosis; (3) explaining that false positive or negative results may occur; (4) informing the subject of the potential consequences of identified seropositivity (psychological reactions, interpersonal problems, social discrimination, possible difficulties in obtaining dental or medical treatment); (5) informing the subject about how the infection is transmitted and how transmission can be prevented; (6) explaining the relative protections offered by confidential testing (Goldblum \& Seymour, 1987; Miller, 1987; Christ et al. 1988). After pre-test counselling, the subject should be ideally given some days to take the final decision whether to undergo the test or not. If he/she decides to proceed, an appointment for blood sampling should be made. Post-test counselling in seropositives involves: (1) presenting the results in a sensitive but honest manner, since any incomplete information may result in a loss of confidence in medical staff and in a reduced motivation to comply with prescribed behavioural changes; (2) informing the subject about HIV-1 infection and AIDS, avoiding any unwarranted estimate of the time left to live or definitive prognosis; (3) prompting the subject to talk about his/her concerns, worries and 
fears; (4) reinforcing the subject's will to fight the infection and to look for a good quality of life; (5) providing human contact and touch; (6) informing the subject of the resources available in the community (self-help groups, AIDS information services), and providing the telephone numbers of the clinic or community counsellors; (7) cautioning the subject against the natural impulse to reveal his/her situation to friends or colleagues, since their reactions cannot be predicted and may have adverse consequences; (8) providing detailed guidelines about safer sex and other precautions aimed to control the infection and avoid its spreading (Miller \& Green, 1986; Christ et al. 1988). Since the above described psychological reactions to the diagnosis may preclude comprehension and change the way in which the subject reacts to others, one counselling session after the test is rarely sufficient. A follow-up within some days should be usually planned, and at that stage the involvement of the partner is desirable.

\section{ADJUSTMENT DISORDERS}

\section{Psychological background}

A morbid (that is, excessive in length and/or intensity) response to the diagnosis of HIV-1 infection or AIDS, or more generally to the stress associated with the disease, can be conditioned by several factors. Subject's coping strategies are certainly involved: Namir et al. (1987) have shown that the style of coping adopted by subjects with a recent diagnosis of AIDS was predictive of their psychological wellbeing, with the highest levels of depression found in those who relied upon avoidance of the reality of the diagnosis, and the highest frequency of obsessive thoughts in those adopting an active-cognitive coping style (involving 'the building of mental defences and the development of a sense of meaning about their illness'). Reservations about homosexuality or lifestyle also seem to be important: in subjects who have internalized social non-acceptance of homosexuality or drug abuse, the diagnosis of HIV-1 infection may be taken as an evidence of past 'wrong doing', thus generating feelings of guilt and self-depreciation (Hays \& Lyles, 1986; Miller, 1988). Previous history of psychiatric disorders has been also regarded as a vulnerability factor (Holland \& Tross, 1985).
Family, occupational and social acceptance is of critical importance: subject's emotional distress can be enhanced by familial estrangement or by the development within the family of a conspiracy of avoidance, because of which the diagnosis is never discussed (Miller, 1988); by over-concern over the impact of diagnosis on the loved-ones; by loss of job or career resulting from the employer's knowledge of the illness; by coexisting financial difficulties. The importance of social support has been recently documented by Zich and Temoshok (1987), who showed that, in patients with ARC or AIDS, the more social support was perceived to be available, the less hopelessness and depression were reported. In this study, emotionally-sustaining social support was rated by the patients to be more desirable than practical support (particularly when coming from lovers, friends or families). Moreover, the possibility was considered that the sickest patients may receive less social support because they are not able to take it up (a finding which is consistent with the observation by Namir et al. (1987) that patients relying on avoidance as a coping style receive less support since they are seen as less motivated and attractive by support givers). Finally, adjustment disorders have been found to be more frequent in subjects with ARC than in those with AIDS (Temoshok et al. 1986; Tross et al. 1986), which finding has been ascribed to the greater level of uncertainty about the future in subjects with mid-stage manifestations of the disease.

\section{Clinical manifestations and prevalence}

The clinical picture of adjustment disorders in subjects with HIV-1 infection or AIDS may be dominated by depression, anxiety, or obsessions and compulsions.

Depression is commonly related by patients to the lack of any effective cure for AIDS; to the apparent inevitability of physical and cognitive decline and future disability; to the present or anticipated social, occupational and sexual rejection; to the restrictions that the illness places on the activities that previously gave a meaning to life (sex, work, travelling, etc.) (Miller, 1987). Depressive symptoms include sadness; feelings of guilt (the patient feels that he/she deserves the illness, and that the current situation is evidence of his/her past misdeeds), worthlessness and helplessness; suicidal 
thoughts (not only based on a desire of selfdestruction, but also on the wish not to be anymore a burden on the loved ones); loss of interest and pleasure in usually enjoyed activities; difficulties with memory and concentration (which may create diagnostic problems with respect to HIV-1 dementia); loss of energy (which may be difficult to distinguish from fatigue occurring as a physical symptom of $A R C$ ), appetite and sexual drive; social withdrawal; sleep disturbances. To what extent depression may impair cellular immunity, thus speeding the progression of HIV-1 infection, remains uncertain.

Anxiety is commonly related by patients to the following issues: the outcome of the infection in the long term, future isolation and abandonment, future loss of physical and financial independence, the risk to infect others or to be infected by them, being identified as a homosexual or a drug abuser, inability by the partner or the family to cope with the situation, possible difficulty in obtaining medical treatment (Miller, 1987). The usual psychic and somatic symptoms of anxiety may all be present. Some of the somatic symptoms (such as diarrhoea, nausea, sweating, fatigue, skin rashes) are similar to those of ARC, so that they may be regarded by the patient as an evidence of the progression of the infection. This produces a further increase of anxiety and possibly a worsening of the somatic symptoms themselves, which confirms the patient's worries.

Obsessive/compulsive symptoms may include mental checking (going over and over past sexual experiences, trying to find out whether past partners showed any sign of illness; going over and over recent activities, trying to identify any event that may have exposed family or friends to the infection); bodily checking or palpating specific bodily areas in order to discover the signs of the illness; obsessional thoughts or mental pictures of physical decline or death.

Adjustment disorders may last many months (WHO, 1988). They have been reported to represent the most frequent diagnosis in patients with ARC or AIDS referred for psychiatric consultation (Dilley et al. 1985; Tross et al. 1986; Rundell et al. 1988; Schaerf et al. 1989). The frequency of these disorders in 85 consecutive consultations from an in-patient AIDS unit has been found to be significantly higher than in 85 consecutive consultations from a general hospital (Schaerf et al. 1989).

\section{Management}

Management of adjustment disorders has been found to benefit from behavioural and cognitive psychotherapy on an individual or group basis, encouraging positive involvement in activities, expression of thoughts and feelings, information-seeking, problem-solving and decision-making, and emphasizing patient's self-worth. Such an approach should involve partners or family members as the patients judge appropriate (Miller, 1989).

Pharmacological treatment of depression and anxiety may be useful. Nevertheless, patients with ARC and AIDS appear to be particularly sensitive to the side-effects of antidepressant drugs, so that low starting doses and small increments should be the rule. It would be desirable to choose drugs with minimal anticholinergic effects, in order to avoid the risk of delirium and extra drying of mucous membranes. Caution is warranted also in the use of benzodiazepines, due to the high liability to drug abuse of some subjects with HIV-1 infection, and the risk of impaired respiratory functioning in patients with Pneumocystis carinii pneumonia (one of the most frequent opportunistic infections occurring in AIDS).

\section{ACUTE PSYCHOTIC DISORDERS}

\section{Psychotic syndromes with evidence of cognitive impairment}

Hallucinations (either visual or auditory) and delusions (either persecutory or grandiose) are not infrequent in patients with ARC or AIDS. They may occur within a context of cognitive impairment, which may be sometimes subtle or fluctuating (Kermani et al. 1984; Nurnberg et al. 1984; Koppel et al. 1985; Perry \& Jacobsen, 1986; Rundell et al. 1986; Beckett et al. 1987; Maccario \& Scharre, 1987; Thomas \& Szabadi, 1987 ), or they may be initially the only psychopathological manifestations, being followed later by such symptoms as disorientation, clouding of consciousness, memory and concentration disturbances (Hoffman, 1984; Navia et al. 1986a). In both these cases, a diagnosis of organic brain syndrome (dementia or delirium) is usually 
warranted. Indeed, many cerebral diseases may present in their early stages with a clinical picture which is indistinguishable from that of a functional psychosis: syphilis is a widely quoted example (Lishman, 1987).

\section{Psychotic syndromes without evidence of cognitive impairment}

There are, however, also reports of patients with otherwise asymptomatic HIV-1 infection, ARC or AIDS who developed acute psychotic disorders without any evidence of cognitive impairment throughout the episode. Thomas et al. (1985) described an HIV-1 seropositive homosexual man who presented with lymphadenopathy and a psychotic syndrome, characterized by persecutory and grandiose delusions and bizarre behaviour, which responded to trifluoperazine. Halevie-Goldman et al. (1987) reported on an HIV-1 seropositive homosexual man presenting with persecutory delusions and auditory hallucinations in the absence of somatic symptoms (outcome not specified). Buhrich et al. (1988) described two subjects with ARC, of whom one presented with blunted affect, multiple delusions and formal thought disorder, and the other with bizarre delusions and behaviour, incongruity of affect and formal thought disorder, both recovering after fluphenazine treatment. Halstead et al. (1988) reported on four cases of HIV-1 infection associated with lability of mood (without a dominant shift towards depression or mania), a variety of delusional beliefs, formal thought disorder and (in three cases) auditory hallucinations of these persons, three improved on neuroleptics and one committed suicide.

The occurrence of acute psychotic disorders without evidence of cognitive impairment in subjects with HIV-1 infection may be interpreted in many ways (Buhrich et al. 1988; VogelScibilia et al. 1988): (1) they may be one of the possible reactions to the diagnosis of HIV-1 infection or AIDS (this was indeed the case in a patient described by Rundell et al. (1986), who became agitated and deluded when told he was seropositive, and rapidly recovered when the results of a repeat test were reported to him as negative); (2) they may be induced by drugs used or abused by the patient (this was the case in a patient described by Campbell (1987), who developed an acute paranoid disorder following a treatment with high-dose methylprednisolone for Pneumocystis carinii pneumonia); (3) they may result from the chance association of psychosis and HIV-1 seropositivity (on the basis of currently available data, this association can be expected to occur by chance in 750 new cases every year within the population of the United States, or even more frequently if one considers that subjects at high-risk for HIV-1 infection and individuals with a first psychotic episode share many features); (4) they may be precipitated by $\mathrm{HIV}-1$ infection in predisposed subjects; (5) they may be directly related to HIV-l infection of the brain. The third and the fifth hypotheses have been regarded as the most plausible in the cases in which knowledge of HIV-1 seropositivity by the subject, drug effects and a personal or family history of psychosis can be excluded (Halstead et al. 1988). A specific vulnerability of dopaminergic systems in AIDS has been suggested by Hollander et al. (1985), and regarded by Maccario \& Scharre (1987) as a possible pathogenic mechanism responsible for schizophreniform psychoses in HIV-1 infected subjects. The predilection of HIV-1 for the limbic system has been also discussed in connection with a case of catatonia in an HIV1 seropositive subject, in whom PET scan showed increased blood flow and glucose metabolism in the right temporal cortex and basal ganglia (Volkow et al. 1987).

\section{Epidemiology and treatment}

The incidence and prevalence of either psychotic symptoms or syndromes in subjects with HIV-I infection, as compared with the general population, is completely unknown. The response of these syndromes and symptoms to neuroleptics has been found to be frequently favourable (Vogel-Scibilia et al. 1988). Nevertheless, AIDS patients have been regarded as susceptible to extrapyramidal side-effects of antipsychotic drugs: the patient described by Maccario \& Scharre (1987) developed parkinsonism after 3 weeks of treatment with haloperidol $2 \mathrm{mg} /$ day, whereas Edelstein \& Knight (1987) reported severe extrapyramidal side effects (including dystonia, rigidity, drooling and akathisia) in two cases treated with the low-potency phenothiazine prochlorperazine $(10 \mathrm{mg}$ every $6 \mathrm{~h})$.

The management of HIV-1 infected patients with acute psychotic disorders may involve 
special practical and ethical dilemmas. If the subject displays out-of-control behaviour which is likely to transmit the virus, and there is a significant risk that such behaviour cannot be controlled by other measures, the question may arise whether the patient's infectious condition can be disclosed to other patients at risk. The position taken by an ad hoc committee of the American Psychiatric Association (1988) is that in these conditions disclosure is permissible. The same committee also concluded that when discharge is otherwise clinically appropriate, if the patient represents a substantial risk to others by virtue of a behaviour known to transmit the virus, but this danger is not related to a specific mental condition, it is inappropriate to retain the person in the hospital solely for quarantine or preventive detention.

\section{MOOD DISORDERS}

\section{Depressive syndromes}

A depressive syndrome not fulfilling ICD-10 criteria for severe depressive episode or DSMIIIR criteria for major depression may occur at any point in the course of HIV-1 infection, but more frequently in the period following the identification of HIV-1 seropositivity (adjustment disorder with depressed mood) or in the initial stage of HIV-1 dementia (WHO, 1988). Moreover, depressive symptoms may result from the occurrence of opportunistic infections or neoplasms (Perry \& Tross, 1984), or from the use of antineoplastic drugs for Kaposi's sarcoma or malignant lymphomas (Chabner \& Myers, 1985; Volberding et al. 1985). It is important to emphasize that depressive symptoms may be difficult to differentiate from some manifestations of ARC (fatigue, anorexia, weight loss, loss of libido, sleep disorders) or of dementia (slowness of mental processes, memory and concentration disturbances).

Major depression has been reported in subjects with HIV-1 infection, but estimates concerning its prevalence have been quite divergent. Perry \& Tross (1984) retrospectively reviewed the charts of 52 AIDS patients admitted to the New York Hospital: mood disturbance was identified in $82.7 \%$ of them, and a DSM-III diagnosis of major depression was made in $17 \cdot 3 \%$. Rundell et al. (1988) reviewed the records of 111 HIV-1 seropositive subjects seen by the psychiatric consultation service at the Medical Center for US Air Force in Texas : a diagnosis of major depression according to DSM-IIIR was made in $3.6 \%$ of subjects. Schaerf et al. (1989), in their already mentioned comparison between 85 consecutive psychiatric consultations from the in-patient AIDS unit of the Johns Hopkins Hospital and 85 consecutive psychiatric general hospital consultations, found that in the former group a diagnosis of major depression was made in $7 \%$ of cases, that is, significantly less frequently than in the latter group. These discrepancies probably reflect the small size of the subject samples and the different sources from which they were recruited. It is also important to stress that the vulnerability to depression may be different in the various groups at risk for HIV-1 infection.

Major depression in HIV-1 infected subjects may be interpreted in several ways: (1) it may result from the above mentioned psychosocial problems related to HIV-1 infection and AIDS; (2) it may be directly related to HIV-1 infection of the brain (in view of the predilection of HIV1 for limbic areas, which are believed to control emotional experience); (3) it may be precipitated by HIV-1 infection in a predisposed subject; (4) it may result from the chance association of affective illness and HIV-1 seropositivity.

\section{Manic syndromes}

A few cases of hypomania or mania in subjects with HIV-1 infection have been also described. In some of them, cognitive impairment was associated or soon developed, thus suggesting a diagnosis of organic brain syndrome (Kermani et al. 1985; Gabel et al. 1986; Perry \& Jacobsen, 1986; Dauncey, 1988; Schmidt \& Miller, 1988); in some others, cognitive impairment did not appear throughout the episode (Buhrich et al. 1988; Schmidt \& Miller, 1988). The possible interpretations of these last cases are similar to those proposed for acute psychotic disorders.

\section{Treatment}

Major depression and mania occurring in subjects with HIV-1 infection have been reported to be usually responsive to the standard treatment with antidepressants or neuroleptics. The previously mentioned susceptibility of HIV-1 infected patients to the side-effects of these drugs should be, however, considered. Indeed, in the 
manic patient described by Gabel et al. (1986), a reaction including diaphoresis, rigidity and pyrexia ensued following treatment with oral trifluoperazine and lithium carbonate, which was interpreted as a neuroleptic malignant syndrome.

\section{SUICIDE}

HIV-1 infection and AIDS have been found to be associated with a high risk of suicide. Marzuk et al. (1988), in a study of the suicide rate in New York City in 1985, reported that the relative risk of suicide in men with AIDS aged 20-59 years was 36.3 times that of men in the same age range without this diagnosis, and 66.15 times that of the general population. All suicides of AIDS patients had occurred within 9 months after receiving the diagnosis, most of them within 6 months. Three suicides $(25 \%)$ had occurred in the medical units of general hospitals (all by jumping from windows). Five of the 12 subjects had seen a psychiatrist within 4 days before suicide (two of them had been treated for depression in a psychiatric hospital within one month before the suicide). Five subjects had expressed suicidal intentions to family, friends, physician or police in the days before their suicide; four subjects had each made one previous suicide attempt (in two cases, the attempt had been made soon after the diagnosis of AIDS). Ten of the 12 subjects were unmarried; nine of them were homosexuals or bisexual. The authors emphasized that the suicide rate reported in the study may be underestimated, since there may have been suicide victims in whom the diagnosis of AIDS was not reported or even not suspected, as well as AIDS patients in whom suicide was not recognized as the cause of death. They listed a number of psychosocial factors which may precipitate suicide in AIDS patients, including the social stigma related to the illness, the withdrawal of family support, diminished or lost occupational functioning, long-term dependency, loss of friends or lovers (often due to AIDS), and the spectre of an inexorable terminal illness that may lead to pain, disfigurement and emaciation. They also pointed out that the presence of concomitant psychiatric syndromes, especially depression and delirium, may increase the rate of suicide in AIDS patients.

The high risk of suicide in HIV-1 infection has been confirmed by Rundell et al. (1988), who found that in 147 HIV-1 seropositive subjects, followed up for an average of 10.8 months by the psychiatric consultation service at the Medical Center for US Air Force in Texas, there were seven suicide attempts and one successful suicide (attempt rate of $4500 / 100000 /$ year). A retrospective analysis revealed the following factors predictive of a suicide attempt: multiple psychosocial stresses, perceived social isolation, perceiving oneself as a victim, reliance on denial as the central or only defence, substance abuse and perceived unavailable social support. Other possible risk factors were disease progression, abnormal CSF, past history of psychiatric illness and personality disorder.

The high risk of suicide in the period following the diagnosis of HIV-1 infection has been confirmed by Miller (1989), who stressed that the likelihood of impulsive suicidal activity is influenced by the manner in which news of the infection is presented, by the availability of social, emotional and practical support, and by the provision of adequate pre- and post-test counselling.

Finally, both Marzuk et al. (1988) and Miller (1989) have mentioned that in some AIDS patients refusal of treatment or reckless activities may represent suicidal equivalents.

\section{AIDS-RELATED PSYCHOPATHOLOGY IN SUBJECTS WITHOUT HIV-1 INFECTION}

\section{Hypochondriacal syndrome (the 'worried well')}

A hypochondriacal syndrome, marked by the persistent belief in the presence of HIV-I infection, despite repeated negative serological tests and clinical examinations, has been described by several authors (Forstein, 1984; Miller, 1986; Hutner \& Zemann, 1988; Miller et al. 1988). It has been pointed out (Miller et al. 1988) that subjects presenting with this syndrome (the 'worried well') should be distinguished from those who become anxious as a result of media coverage of AIDS and therefore require HIV-1 serology, but who experience long-term reassurance following negative laboratory and clinical findings.

The clinical features of the 'worried well' include anxiety, with the possible occurrence of panic attacks (triggered by media coverage of 
AIDS or social discussion of the topic); anxietybased physical symptoms and signs (fatigue, sweating, skin rashes, muscle pains, diarrhoea, palpable lymph nodes), which are misinterpreted as manifestations of HIV-I infection; obsessive thoughts (ruminations over past high-risk sexual practices, threats of infection to the loved ones, dirtiness or infectivity of bodily fluids); compulsive behaviour (palpating specific bodily areas or checking for Kaposi's sarcoma lesions, washing sources of potential contamination); depression with possible suicidal behaviour and/or substance abuse. A high rate of recent attendance of medical services is the rule (JägerCollet, 1988; Miller, 1988).

The 'worried well' usually give very detailed and dramatic descriptions of their bodily symptoms. They frequently ascribe the negativity of their laboratory tests to the fact that the current methods cannot offer a $100 \%$ assurance, or that they are among the few persons who cannot form antibodies against HIV-1, or that they have been infected by a mutated or new virus which cannot be identified by currently available tests (Hutner \& Zemann, 1988). Very often, the basis given for the supposed HIV-1 infection is a sexual contact, mostly with a person who is not the steady partner (Hualla \& Jaeger, 1988). A severe social disability, with avoidance of possible sexual partners and abandonment of professional activities, may occur in some cases.

Difficulties in sexual adjustment have been almost consistently observed in the "worried well'. Indeed, it has been maintained that in some of these individuals the public anxiety about AIDS appears to act as a vehicle for the expression of sexual guilt or anxiety (Miller $e t$ al. 1988). Hutner \& Zemann (1988) have reported that, with few exceptions, the 'worried well' do not belong to the principal groups at risk for HIV-1 infection, but Miller et al. (1988) have found that 11 of their 19 patients were homosexual or bisexual, although almost all of them had a recent history of low-risk sexual activity. A past history of psychiatric disorders (mostly depression and anxiety) has been found to be frequent.

The differential diagnosis of HIV-1 related hypochondriacal syndrome may be difficult. In particular, the possibility that a psychosis is concealed behind the hypochondriacal complaints should be considered (Naber \& Hippius,
1988). The way in which the belief of infection is presented may be important: a bizarre, delusional pattern can be the first indication of the presence of a psychosis.

The management of the 'worried well ' appears to benefit from a cognitive-behavioural approach, involving: (1) the re-interpretation of symptoms in terms of anxiety rather than manifestations of HIV-1 infection; (2) the institution of a stress inoculation training (Hedge et al. 1988; Miller et al. 1988).

\section{Other AIDS-related psychopathology}

Other AIDS-related psychopathology in subjects without HIV-1 infection includes delusions of having AIDS in psychotic patients, attempts to commit suicide by contracting AIDS, and factitious AIDS.

It is well known that psychotic patients tend to incorporate in their delusions topics that are of public interest at the moment. Since AIDS has become a subject of increasing public concern, it is not surprising that several authors have described delusions of having contracted AIDS in patients suffering from major depression with psychotic features, schizoaffective disorder or paranoid schizophrenia (Rapaport \& Braff, 1985; Lawlor \& Stewart, 1987; O’Brien, 1987; Altamura et al. 1988; Mahorney \& Cavenar, 1988; Shetty, 1988). In these cases, delusions resolved with adequate treatment of the underlying disorder. AIDS delusions appear to be more frequent in depressed patients, which has been ascribed to the fact that the concept of having AIDS represents an ideal delusion for a patient whose sense of guilt seeks a tangible form, especially if the dynamic source of guilt is sexual indiscretion (Mahorney \& Cavenar, 1988).

It is also not surprising that some subjects have deliberately sought to be infected by AIDS with the aim of committing suicide (Frances $e t$ al. 1985; Flavin et al. 1986; Papathomopoulos, 1988). The risk of this behaviour has been reported to be the highest in homosexual men who are depressed, alcoholic and passively selfdestructive. It has been suggested that these subjects project murderous wishes by seeking out another as an 'executioner' (Flavin et al. 1986).

Two cases of factitious AIDS have been reported by Miller et al. (1986). Both were 
homosexual men who presented themselves as having AIDS but whose physical examinations were negative. In one of them the challenge of the diagnosis was followed by a psychotic response, and the factitious disorder was interpreted as an attempt to prevent severe decompensation by expressing it as a physical illness.

\section{CONCLUDING COMMENTS}

The information summarized in the present review should be regarded as provisional, for the following reasons: (1) many of the studies from which it is derived appear to be weak from the methodological viewpoint, being based on retrospective evaluation of small samples (or even single cases) without or with inadequate control groups; (2) the majority of these studies have been carried out in Western countries and in samples of homosexual and bisexual men, so that the generalizability of the findings is uncertain; (3) no large community study is at present available, and data concerning the prevalence of the various disorders are either lacking or clearly conditioned by the type of facilities where the investigation has been conducted; (4) very few longitudinal studies have been carried out until now, so that the natural history of HIV-I associated conditions remains largely unknown; (5) the clinical characterization of some HIV-I associated disorders is currently not precise, which hampers the comparability of the results obtained by the different groups (for instance, no operational diagnostic criteria have been as yet provided for HIV-I dementia, and no agreement exists, therefore, about how many and which cognitive, behavioural and motor symptoms and signs are required in order to diagnose this condition); (6) the prevalence of several psychiatric disorders is apparently higher in some groups at risk for HIV-I infection than in the general population, so that assumptions concerning a causal relationship between HIV-1 infection or disease and the observed psychopathology appear sometimes to be unwarranted.

Anyway, the evidence provided by the currently available scientific literature suggests that the impact of HIV-1 infection on psychiatric services is going to become dramatic worldwide. There is clearly a need for facilities (beds for short- and long-term care, out-patient units, day-care centres), but especially a need for health care professionals with adequate training and positive attitudes towards AIDS patients. Moreover, it is now quite evident that AIDS care providers need support in their turn. Facing AIDS epidemic, therefore, requires a network of services which in some contexts will not easily become available. On the other hand, the challenge posed by HIV-I infection and AIDS may represent a favourable opportunity for the development of community-based teams in sites where they are not available, and for the establishment of a closer link between psychiatry and general medicine in contexts where the isolation of the places where psychiatric care is provided is still a reality.

\section{REFERENCES}

Altamura, C. A., Mauri, M. C., Coppola, M. T. \& Cazzullo, C. L. (1988). Delusional AIDS and depression. British Journal of Psychiatry' 153, 267269.

American Psychiatric Association Ad Hoc Committee on AIDS Policy (1988). AIDS policy: guidelines for inpatient psychiatric units. American Journal of Psychiatry' 145, 542.

Beckett, A., Summergrad, P., Manschreck, T., Vitagliano, H., Henderson, M., Buttolph, M. L. \& Jenike, M. (1987). Symptomatic HIV infection of the CNS in a patient without clinical evidence of immune deficiency. American Journal of Psychiatry 144, 13421343.

Brew, B. J., Bhalla, R., Paul, M., Schwar(z, M. \& Price, R. W. (1989).

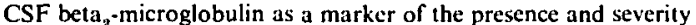
of AIDS dementia complex. Abstracts V International Conference on AIDS, p. 454.

Buhrich, N., Cooper, D. A. \& Freed, E. (1988). HIV infection associated with symptoms indistinguishable from functional psychosis. British Journal of Psychiatry 152, 649653.

Campbell, I. A. (1987). Aggressive psychosis in AIDS patient on high-dose steroids. Lance't i, 750751.

Chabner, B. A. \& Myers, C. E. (1985). Clinical pharmacology of cancer. In Cancer: Principles and Practice of Oncology (ed. V. T. De Vita, C. Hellman, S. A. Rosenberg), pp. 287 328. Lippincott: Philadelphia.

Christ, G. H., Siegel, K. \& Moynihan, R. T. (1988). Psychosocial issues: prevention and treatment. In $A I D S$ : Etiology, Diagnosis, Treatment and Prevention, 2nd ed. (ed. V. T. De Vita, S. Hellman and S. A. Rosenberg), pp. 321 337. Lippincott: Philadelphia.

Currie, J. N., Benson, E. M., Ramsden, B. M., Lynch, J. M., McArthur, C. L. \& Cooper, D. A. (1989). Clinical validation of a bedside antisaccadic test for the assessment of AIDS dementia. Abstracts V International Conference on AIDS, p. 465.

Dauncey, K. (1988). Mania in the early stages of AIDS. British Journal of Psychiatry 152, 716717.

Deuchar, N. (1984). AIDS in New York City with particular reference to the psycho-social aspects. British Journal of Psychiarry' $145,612.619$.

Dilley, J. W., Ochitill, H. N., Perl, M. \& Volberding, P. (1985). Findings in psychiatric consultations with patients with acquired immune deficiency syndrome. American Journal of Psychiatry 142 , 8286.

Edelstein, H. \& Knight, R. T. (1987). Severe parkinsonism in two AIDS patients taking prochlorperazine. Lancet ii, 341342.

Epstein, L. G., Scharer, L. R., Cho, E.-S., Meyenhofer, M., Navia, B. A. \& Price, R.W. (1985). HTLV-IIl/LAV-like retrovirus particles in the brains of patients with AIDS encephalopathy. AIDS Research 1, 447-454. 
Flavin, D. K., Franklin, J. E. \& Frances, R. J. (1986). The acquired immune deficiency syndrome (AIDS) and suicidal behaviour in alcohol-dependent homosexual men. American Journal of Psychiatry 143, 1440-1442.

Forstein, M. (1984). The psychosocial impact of acquired immunodeficiency syndrome. Seminars on Oncology 11, 77-88.

Frances, R. J., Wikstrom, T. \& Alcena, V. (1985). Contracting AIDS as a means of committing suicide. American Journal of Psychiatry 142. 656 .

Gabel, R. H., Barnard, N., Norko, M. \& O'Connell, R. A. (1986). AIDS presenting as mania. Comprehensive Psychiatry 27, 251-254.

Gabuzda, D. H., Ho, D. D., de la Monte, S. M., Hirsch, M. S., Rota, T. R. \& Sobel, R. A. (1986), Immunohistochemical identification of HTLV-III antigen in brains of patients with AIDS. Annals of Neurology' 20, 289-295.

Gartner, S., Markovits, P., Markovitz, D. M., Betts, R. F. \& Popovic, M. (1986). Virus isolation from and identification of HTLV-III/LAV-producing cells in brain tissue from a patient with AIDS. Journal of the American Medical Association 256, 2365-2371.

Goebel, F.-D., Bogner, J. R., Junge-Hülsing, B., Matuschke, A., Heinrich, G. \& Einhăupl, K. (1989). Neopterin and beta $\mathbf{2}_{2}$ microglobulin in cerebrospinal fluid in HIV-infection. Abstracts V International Conference on AIDS, p. 456.

Goethe, K. E., Mitchell, J. F., Marshall, D. W., Brey, R. L., Cahill, W. T., Leger, G. D., Hoy, L. J. \& Boswell, R. N. (1989). Neuropsychological and neurological function of human immunodeficiency virus seropositive asymptomatic individuals. Archives of Neurology 46, 129133.

Goldblum, P. \& Seymour, N. (1987). Whether to take the test: counselling guidelines. Focus: A Guide to AIDS Research 2, 1.

Grant, I., Atkinson, J. H., Kennedy, C., McCutchan, J. A., Richman, D. D. \& Spector, S. A. (1987a). Neuropsychological findings in HIV infection: relation to seropositivity and treatment with azidothymidine. Journal of Clinical and Experimental Neuropsychology' 9, 261.

Grant, L. Atkinson, J. H., Hesselink, J. R., Kennedy, C. J., Richman, D. D., Spector, S. A. \& McCutchan, J. A. (1987b). Evidence for early central nervous system involvement in acquired immunodeficiency syndrome (AIDS) and other human immunodeficiency virus (HIV) infections: studies with neuropsychological testing and magnetic resonance imaging. Annals of Internal Medicine 107 , $828 \cdot 836$.

Halevie-Goldman, B. D., Potkin, S. G. \& Poyourow, P. (1987). AIDS-related complex presenting as psychosis. American Journal of Psychiarry 144, 964.

Halstead, S., Riccio, M., Harlow, P., Oretti, R. \& Thompson, C. (1988). Psychosis associated with HIV infection. British Journal of Psychiatry 153, 618-623.

Hays, L. R. \& Lyles, M. R. (1986). Psychological stresses in patients with acquired immune deficiency syndrome. American Journal of Psychiatry 143, 551.

Hedge, B., Acton, T. M. G. \& Miller, D. (1988). The worried well : a cognitive-behavioural understanding and intervention. Abstracts IV International Conference on AIDS, Book 2, p. 402.

Heyes, M. P., Brew, B. J., Markey, S. P., Martin, A., Price, R. W., Rubinow, D. \& Salazar, A. M. (1989). Quinolinic acid concentrations are increased in plasma and cerebrospinal fluid in AIDS and correlates with AIDS dementia complex. Abstracts $V$ International Conference on AIDS, p. 454.

Ho, D. D., Rota. T. R., Schooley, R. T., Kaplan, J. C., Allan, J. O., Groopman, J. E., Resnick, L., Felsenstein, D., Andrews, C. A. \& Hirsch, M.S. (1985). Isolation of HTLV-III from cerebrospinal fluid and neural tissue of patients with neurologic syndromes related to the acquired immunodeficiency syndrome. New England Journal of Medicine 313, $1493-1497$.

Hoffman. R. S. (1984). Neuropsychiatric complications of AIDS. Psychosomatics 25, 393400.

Holland, J. C. \& Tross, S. (1985). The psychosocial and neuropsychiatric sequelae of the acquired immunodeficiency syndrome and related disorders. Annals of Internal Medicine 103, 760-764.

Hollander, H., Golden, J., Mendelson, T. \& Cortland, D. (1985).
Extrapyramidal symptoms in AIDS patients given low-dose metoclopramide or chlorpromazine. Lancet ii, 1186.

Hualla, T. \& Jäger, H. (1988). The Swabian study of AIDS phobics. In AIDS Phobia (ed. H. Jäger), pp. 115-122. Ellis Harwood: Chichester.

Hutner, G. \& Zemann, R. (1988). Experiences with AIDS phobics in advisory centres. In AIDS Phobia (ed. H. Jäger), pp. 79-83. Ellis Harwood: Chichester.

Jäger-Collet, B. (1988). The disease pattern in psychological practice. In AIDS Phobia (ed. H. Jäger), pp. 71-77. Ellis Harwood: Chichester.

Janssen, R.S. (1989). HIV and the nervous system. In AIDS: Principles, Practices and Politics (ed. I. B. Corless and M. PittmanLindeman), pp. 55-60. Hemisphere: New York.

Janssen, R. S., Stehr-Green, J. \& Starcher, T. (1989a). Epidemiology of HIV encephalopathy in the United States. Abstracts $V$ International Conference on AIDS, p. 50.

Janssen, R. S., Saykin, A. J., Cannon, L., Campbell, J., Pinsky, P. F., Hessol, N. A., O'Malley, P. M., Lifson, A. R., Doll, L. S., Rutherford, G. W. \& Kaplan, J. E. $(1989 \mathrm{~b})$. Neurologic and neuropsychologic manifestations of human immunodeficiency virus (HIV-I) infection: association with AIDS-related complex but not asymptomatic HIV-1 infection. Annals of Neurology 26, $592-600$.

Jensen, P. C., Hubesch, G., Parks, R., Deicken, R., Krell, P. \& Weiner, M. W. (1989). Altered brain metabolites in AIDS dementia as measured by magnetic resonance spectroscopy. Abstracts $V$ International Conference on AIDS, p. 603.

Kermani, E. J., Drob, S. \& Alpert, M. (1984). Organic brain syndrome in three cases of acquired immune deficiency syndrome. Comprehensive Psychiatry 25, 294-297.

Kermani, E. J., Borod, J. C., Brown, P. H. \& Tunnel, G. (1985). New psychopathological findings in AIDS: case report. Journal of Clinical Psychiatry 46, 240-241.

Koenig, S., Gendelman, H. E., Orenstein, J. M., Dal Canto, M. O., Pezeshkpour, G. H., Yungbluth, M., Janotta, F., Akasamit, A., Martin, M. A. \& Fauci, A. S. (1986). Detection of AIDS virus in macrophages in brain tissue from AIDS patients with encephalopathy. Science 233, 1089-1093.

Koppel, B. S., Wormser, G. P., Tuchman, A. J., Manyan, S., Hewlett, D. \& Daras, M. (1985). Central nervous system involvement in patients with acquired immune deficiency syndrome (AIDS). Acta Neurologica Scandinavica 71, 337-353.

Lawlor, B. A. \& Stewart, J. T. (1987). AIDS delusions: a symptom of our times. American Journal of Psychialry 144, 1244.

Lee, M. R., Ho, D. D. \& Gurney, M. E. (1987). Functional interaction and partial homology between human immunodeficiency virus and neuroleukin. Science 237, 1047 1051.

Lishman, W. A. (1987). Organic Psychiatry. Blackwell: Oxford.

McArthur, J. C. (1987). Neurologic manifestations of AIDS. Medicine $66,407-437$.

Maccario, M. \& Scharre, D. W. (1987). HIV and acute onset of psychosis. Lancet ii, $\mathbf{3 4 2}$.

Mahorney, S. L. \& Cavenar, J. O. Jr. (1988). A new and timely delusion: the compliant of having AIDS. American Journal of Psychiairy 145, 1130.

Marzuk, P. M., Tierney, H., Tardiff, K., Gross, E. M., Morgan, E. B., Hsu, M.-A. \& Mann, J. J. (1988). Increased risk of suicide in persons with AIDS. Journal of the American Medical Association 259, 1333-1337.

Miller, D. (1986). The worried well. In The management of AIDS Patients (ed. D. Miller, J. Weber and J. Green), pp. 169-173. Macmillan: Houndmills.

Miller, D. (1987). Living with AIDS and HIV. Macmillan: Houndmills.

Miller, D. (1988). HIV and social psychiatry. British Medical Bulletin 44, 130-148.

Miller, D. (1989). Functional psychiatric syndromes associated with HIV-I infection and disease. Paper presented at the meeting on 'Neurological and neuropsychological complications of HIV infection', Quebec City, 21 May-3 June, 1989. 
Miller, D. \& Green, J. (1986). Counselling for HIV infection and AIDS. Clinics in Immunology and Allergy 6, 661-683.

Miller, D., Acton, T. M. G. \& Hedge, G. (1988). The worried well: their identification and management. Journal of the Royal College of Physicians of London 22, 26-33.

Miller, F., Wesden, P., Sacks, M. \& Woznia, J. (1986). Two cases of factitious acquired immune deficiency syndrome. American Journal of Psychiatry 143, 1483.

Morin, S. F., Charles, K. A. \& Malyon, A. K. (1984). The psychological impact of AIDS on gay men. American Psychologist 39, $1288-1293$.

Moskowitz, L. B., Hensley, G. T., Chan, J. C., Conley, F. K., Donovan-Post, M. J. \& Gonzales-Arias, S. M. (1984). Brain biopsies in patients with acquired immunodeficiency syndrome. Archives of Pathology and Laboratory Medicine 108, 368-371.

Muluka, E. A. P. (1988). Neuropsychiatric complications of HIV infection at Kenyatta National Hospital, Kenya. Paper presented at the WHO Consultation on neuropsychiatric aspects of HIV infection. Geneva, 14-17 March, 1988.

Naber, D. \& Hippius, H. (1988). Inpatient psychiatric management of AIDS phobia. In AIDS Phobia (ed. H. Jäger), pp. 85-94. Ellis Harwood: Chichester.

Namir, S., Wolcott, D. L., Fawzy, F. I. \& Alumbaugh, M. J. (1987). Coping with AIDS: psychological and health implications. Journal of Applied Social Psychology 17, 309-328.

Navia, B. A., Jordan, B. D. \& Price, R. W. (1986a). The AIDS dementia complex: I. Clinical features. Annals of Neurology 19. $517-524$

Navia, B. A., Cho, E.-S., Petito, C. K. \& Price, R. W. (1986b). The AIDS dementia complex : II. Neuropathology. Annals of Neurology 19, 525-535.

Nichols, S. E. (1985). Psychosocial reactions of persons with the acquired immunodeficiency syndrome. Annals of Internal Medicine $103,765-767$.

Nielsen, S. L., Petito, C. K., Urmacher, C. S. \& Posner, J. B. (1984). Subacute encephalitis in acquired immune deficiency syndrome: a postmortem study. American Journal of Clinical Pathology 82, 678-682.

Nurnberg, H. G., Prudic, J., Fiori, M. \& Freedman, E. P. (1984). Psychopathology complicating acquired immune deficiency syndrome (AIDS). American Journal of Psychiatry 141, 95-96.

O'Brien, L. S. (1987). Not a case of pseudo-AIDS. British Journal of Psychiatry' 151, 127.

Olsen, W. L., Longo, F. M., Mills, C. M. \& Norman, D. (1988). White matter disease in AIDS: findings at MR imaging. Radiology $169,445-448$.

Papathomopoulos, E. (1988). Deliberate HIV infection as a means of committing suicide. Abstracts IV International Conference on AIDS, Book 2, p. 407.

Paul, M. O., Brew, B. J., Khan, A., Gallardo, M. \& Price, R. W. (1989). Detection of HIV-I in cerebrospinal fluid (CSF): correlation with presence and severity of the AIDS dementia complex. Abstracts V International Conference on AIDS, p. 238.

Perry, S. \& Jacobsen, P. (1986). Neuropsychiatric manifestations of AIDS-spectrum disorders. Hospital and Community Psychiatry 37, 135-142.

Perry, S., Belsky-Barr, D., Barr, W. B., Jacobsberg, L. (1989). Neuropsychological function in physically asymptomatic, HIV. seropositive men. Journal of Neuropsychiatry 1, 296-302.

Perry, S. W. \& Tross, S. (1984). Psychiatric problems of AIDS patients at the New York Hospital: preliminary report. Public Health Reporss 39, 200-205.

Price, R. W., Brew, B., Sidtis, J., Rosenblum, M., Scheck, A. C. \& Cleary, P. (1988a). The brain in AIDS: central nervous system HIV-1 infection and AIDS dementia complex. Science 239, 586-592.

Price, R. W., Sidtis, J. J., Navia, B. A., Pumarola-Sune, T. \& Ornitz, D. B. $(1988 b)$. The AIDS dementia complex. In AIDS and the Nervous System (ed. M. L. Rosenblum, R. M. Levy and D. E. Bredesen), pp. 203-219. Raven Press: New York.

Pumarola-Sune, T., Navia, B. A., Cordon-Cardo, C., CHo, E.-S. \&
Price, R. W. (1987). HIV antigen in the brains of patients with the AIDS dementia complex. Annals of Neurology' 21, 490 496.

Rapaport, M. \& Braff, D. L. (1988). AIDS and homosexual panic. American Journal of Psychiatry 142, 1516.

Raphael, B., Kelly, B. \& Greig, R. (1989). The neuropsychiatric aspects of human immunodeficiency virus infection and the acquired immunodeficiency syndrome: service implications. Medical Journal of Australia 150, 473475.

Raske, K. E. (1988). The impact of AIDS on New York's not-forprofit hospitals. New York State Journal of Medicine 88, 247--262.

Rottenberg, D. A., Moeller, J. R., Strother, S. C., Sidtis. J. J., Navia, B. A., Dhawan, V., Ginos, J. Z. \& Price, R. W. (1987). The metabolic pathology of the AIDS dementia complex. Annals of Neurology 22, 700-706.

Rundell, J. R., Wise, M. G. \& Ursano, R. J. (1986). Three cases of AIDS-related psychiatric disorders. American Journal of Psychiatry 143, 777-778.

Rundell, J., Thomason, J., Zajac, R. \& Beatty, R. (1988). Psychiatric diagnosis and attempted suicide (AS) in HIV infected USAF personnel. Abstracts IV International Conference on AIDS, Book 2, p. 407.

Sacerdote, P., Ruff, M. R. \& Pert, C. B. (1987). Vasoactive intestinal peptide 1-12: a ligand for the CD4 (T4)/human immunodeficiency virus receptor. Journal of Neuroscience Research 18, 102-107.

Schaerf, F. W., Koenig, T. \& Wisner-Carlson, B. (1989). Frequency of psychiatric disorders in hospitalized AIDS patients: comparison to a general hospital population. Abstracts $\mathrm{V}$ International Conference on AIDS, p. 388.

Schmidt, U. \& Miller, D. (1988). Two cases of hypomania in AIDS. British Journal of Psychiatry 152, 839.842.

Schmitt, F. A., Bigley, J. W., McKinnis, R., Logue, P. E., Evans, R. W. \& Drucker, J. L. (1988). Neuropsychological outcome of zidovudine (AZT) treatment of patients with AIDS and AIDSrelated complex. New England Journal of Medicine 319, 1573-1578. Seidl, O. \& Goebel, F. (1987). Psychosomatic reactions of homosexuals and drug addicts to the knowledge of a positive HIV test result. AIDS-Forschung 4, 181-187.

Selnes, O. A., McArthur, J. C., Miller, E. N., Sheridan, K., Becker, J. T. \& Gordon, B. (1989). Further evidence of lack of HIV-i related cognitive impairment during the asymptomatic stages: the Multicenter AIDS Cohort Study (MACS). Abstracts V International Conference on AIDS, p. 210.

Shaw, G. M., Harper, M. E., Hahn, B. H., Epstein, L. G., Gajdusek, O. C., Price, R. W., Navia, B. A., Petito, C. K., O'Hara, C. J., Cho, E.-S., Oleske, J. M., Wong-Staal, F. \& Gallo, R. C. (1985). HTLV-III infection in brains of children and adults with AIDS encephalopathy. Science 227, 177.182.

Shetty, G. C. (1988). Depressive illness with delusions of AIDS. American Journal of Psychiatry 145, 765.

Sidtis, J. J., Thaler, H., Brew, B. J., Sadler, A. E., Keilp, J. G., Aranow, H. A. \& Price, R. W. (1989). The interval between equivocal and definite neurological signs and symptoms in the AIDS dementia complex (ADC). Abstracts $\mathrm{V}$ International Conference on AIDS, p. 215.

Snider, W. D., Simpson, D. M., Nielsen, G., Gold, J. W. M., Metroka, C. \& Posner, J. B. (1983). Neurological complications of acquired immune deficiency syndrome: analysis of 50 patients. Annals of Neurology 14, 403418.

Stempel, R., Moulton, J., Kelly, T., Osmond, D. \& Moss, A. (1987). Patterns of distress following HIV antibody test notification. Abstracts III International Conference on AIDS, p. 143.

Temoshok, L., Mandel, J. S., Moulton, J. M., Solomon, G. \& Zich, J. (1986). A longitudinal psychosocial study of AIDS and ARC in San Francisco. Paper presented at the 13th Annual Meeting of the American Psychiatric Association, Washington, 13 May, 1986.

Thomas, C. S. \& Szabadi, E. (1987). Paranoid psychosis as the first presentation of fulminating lethal case of AIDS. British Journal of Psychiatry 151, 693 695.

Thomas, C. S., Toone, B. K., El Kamy, A., Harwin, B. \& Farthing, C. P. (1985). HTLV-III and psychiatric disturbance, Lancet ii, 395 . Tross, S., Holland, J., Hirsch, D., Schiffman, M., Gold, J. \& Safai, 
B. (1986). Psychological and social impact of AIDS spectrum disorders. Abstracts II International Conference on AIDS, p. 157.

Tross, S., Price, R. W., Navia, B., Thaler, H. T., Gold, J., Hirsch, D. A. \& Sidtis, J. J. (1988). Neuropsychological characterization of the AIDS dementia complex : a preliminary report. AIDS 2, 81-88.

Vazeux, R.. Brousse, N., Jarry, A., Henin, D., Marche, C., Vedrenne, C., Mikol, J., Wolf, M., Michon, C., Rozenbaum, W., Bureau, J.-F., Montagnier, L. \& Brahic, M. (1987). AIDS subacute encephalitis: identification of HIV-infected cells. American Journal of Pathology 126, 403-410.

Vogel-Scibilia, J. E., Mulsant, B. H. \& Keshavan, M. S. (1988). HIV infection presenting as psychosis: a critique. Acta Psychiatrica Scandinavica 78, 652656

Volberding, P. A., Abrams, D. I. \& Conant, M. (1985). Vinblastin therapy for Kaposi's sarcoma in the acquired immunodeficiency syndrome. Annals of Internal Medicine 103, 335-338.
Volkow, N. D., Harper, A., Munnisteri, D. \& Clother, J. (1987). AIDS and catatonia. Journal of Neurology, Neurosurgery and Psychiatry 50, 104

World Health Organization (1988). Report of the consultation on the neuropsychiatric aspects of HIV infection, Geneva, 14.17 March, 1988. WHO: Geneva.

Yarchoan, R., Berg, G., Brouwers, P., Fischl, M. A., Spitzer, A. R. Wichman, A., Grafman, J., Thomas, R. V., Safai, B., Brunetti, A. Perno, C. F., Schmidt, P. J., Larson, S. M., Myers, C. E. \& Broder, S. (1987). Response of human-immunodeficiency-virus-associated neurological disease to $3^{\prime}$-azido-3'-deoxythymidine. Lancet. i, 132-135.

Zich, J. \& Temoshok, L. (1987). Perceptions of social support in patients with ARC and AIDS. Journal of Applied Social Psychiatry $17,123-125$. 